\title{
Nathaniel Bowditch and the Power of Numbers: How a Nineteenth-Century Man of Business, Science, and the Sea Changed American Life. By Tamara Plakins Thornton. Chapel Hill: University of North Carolina Press, 2016. Pp. xiv, 402. \$35 cloth. doi: $10.1017 / \mathrm{S} 0022050717000419$
}

Nathaniel Bowditch (1773-1838) was born into a poor but respectable and wellconnected family in Salem, Massachusetts. He had little formal schooling, but showed a remarkable aptitude for mathematics, which he learned as a shop's apprentice clerk. As a young man he made several sea voyages to the East Indies, acting as a supercargo and applying his interest in mathematics to navigation at sea, gaining renown with the publication of his New American Practical Navigator in 1802, a substantial improvement on earlier, error-filled navigation aids.

In 1804, Bowditch was appointed president of the Essex Fire and Marine Insurance Company, where he gained a reputation for integrity and efficient management and rose to become one of Salem's leading citizens, all the while continuing to pursue his interest in mathematics. In 1823 he relocated to Boston to run the Massachusetts Hospital Life Insurance Company, which, despite its name, was primarily concerned with investing the wealth of Boston's elite. Under Bowditch's prudent and at times uncompromising leadership, the MHL prospered and developed into a major financial institution. Bowditch's fortune and reputation continued to grow, and he later played an important role in reforming the organization of other key Boston institutions. He also attained modest scientific prominence by publishing several scientific articles, and near the end of his life, published an annotated English translation of Laplace's magnum opus, Mécanique Céleste. This important work further enhanced Bowditch's reputation, and earned him election to the most important learned societies of Europe, making him one of the few Americans to achieve such recognition in this period.

Bowditch's accomplishments have previously been celebrated in other biographies, including a eulogistic memoir published by his son shortly after his death, and Robert Elton Berry's 1941 biography, Yankee Stargazer, which emphasized Bowditch's early seafaring years in Salem. In the century after his death a narrative developed of Bowditch as a self-made man of obscure birth who rose to prominence through merit. Tamara Thornton's excellent new biography goes far beyond these earlier works. While not wholly denying the picture of the self-made man, Thornton also emphasizes the importance of personal connections and a respectable family background that gave Bowditch's undoubted merit a chance to shine through. She also shifts the focus from Bowditch's early practical achievements as a navigator and his later scientific accomplishments to his role in transforming the administrative operations of several important Boston institutions.

The book is written in an engaging style with a good dose of wry humor, and enlivened with excursions into a wide variety of topics including navigation, trade, insurance, astronomy, early American politics, the role of learned societies, and the practice of science in the early nineteenth century. Throughout, Thornton does a wonderful job of turning what could at times be rather dry material into a real page-turner by keeping the focus squarely on biography, bringing the relationships among people, their personal triumphs and tragedies, and their maneuvering for social and political advantage, vividly to life. She paints a rounded picture of Bowditch as a man with a loving family life and genuine religious convictions, whose humble roots and lack of formal education and social polish prevented him from ever becoming fully accepted in some circles. Yet Thornton also provides a clear and satisfying treatment of technical issues, doing 
justice to the details without getting bogged down in them. She has a knack for bringing excitement to topics such as the method for finding lunars to determine longitude, or the correction of computational errors in nautical tables (an important plot point).

Many early American corporations were characterized by haphazard business procedures, ad-hoc record-keeping, and lax oversight. As the mode of business evolved from flexible, informal and personal relationships towards more impersonal transactions, it became necessary to systematize business practices and to keep careful and standardized records. At the MHL, Bowditch implemented a vision of the corporation as an impartial, impersonal bureaucratic "machine," introducing clear administrative structures, systematic record-keeping, and the use of blank printed forms to record transactions. As a trustee at the Boston Athenaeum, he greatly improved the organization of the book collection, and he also engaged in rather ruthless political maneuvering to remove those he considered guilty of sloppy management, both at the Athenaeum, and as a fellow of Harvard's governing board, where he forced the resignations of several faculty and administrators, including a president.

From this aspect of Bowditch's activities, Thornton draws out the overarching theme of the book: that the mathematical prodigy Bowditch was driven to apply the methodical principles of mathematics and science to the world of corporate organization, and in the process, "transformed the world of practical affairs" and "changed American life." While this serves as an interesting device for binding the narrative together, it is neither wholly convincing, nor really necessary to make the book interesting. Many early corporations struggled to deal with a variety of agency problems, and similar modernizing organizational changes were implemented in both public and private institutions on both sides of the Atlantic. Bowditch was certainly an early leader in this effort in Boston, but it is not clear that approach to corporate organization was truly unique, or that his influence spread beyond the few organizations with which he was involved. Moreover, although he is at times represented as insisting on iron adherence to rigid, impersonal rules, the book also makes clear that in practice, the rules were often applied flexibly — even by Bowditch — and that the use of personal relationships, and privileged treatment for the well-connected, remained the norm throughout this period. Ultimately, it is not clear to what extent Bowditch should be viewed as a visionary innovator rather than as an interesting exemplar of a broader trend.

Either way, however, any reader interested in early American life in general, and particularly the development of early American corporations, will find this engaging and deeply researched biography an enjoyable and rewarding read.

Christopher Kingston, Amherst College

ASIA

The Age of Gunpowder, China, Military Innovation, and the Rise of the West in World History. By Tonio Andrade. Princeton and Oxford: Princeton University Press, 2016. Pp. IX, 432. \$39.95, hardcover. doi: $10.1017 / \mathrm{S} 0022050717000201$

This is a well-written and well-edited book. Its author evidently is familiar with the specifics of his topic as well as with the broader debates for which it can be made relevant. He provides a balanced mix of small facts and large issues and has clear 